\title{
Sleep lifestyle correlate of dizziness among teachers
}

\author{
Daiane Soares de Almeida Ciquinato ${ }^{10}$ Paula Carolina Dias Gibrin ${ }^{10}$ Carla Juliana Lotti Félix ${ }^{1,2(1)}$ \\ Jessica Aparecida Bazoni ${ }^{10}$ Luciana Lozza de Moraes Marchiori,30
}

${ }^{1}$ Doctoral Program in Rehabilitation Sciences, Universidade Estadual de Londrina/Universidade Norte do Paraná, Londrina, PR, Brazil

${ }^{2}$ Scholarship Undergraduate Research, Pitágoras Unopar, Londrina, PR, Brazil

${ }^{3}$ Centro Universitário de Maringá (Unicesumar), Maringa, PR, Brazil
Address for correspondence Daiane Soares de Almeida Ciquinato, Master, Programa de Doutorado em Ciências de Reabilitação, Universidade Estadual de Londrina/Universidade Norte do Paraná (UEL/UNOPAR), Londrina, PR, Brazil

(e-mail: ciquinato19@gmail.com; daiane.ciquinato@bol.com.br).

Int Arch Otorhinolaryngol 2021;25(2):e213-e218.

\begin{abstract}
Keywords

- dizziness

- sleep quality

- school teachers

- rehabilitation

Introduction Some studies have shown associations between sleep quality and dizziness. However, this association has not been investigated in teachers.

Objective To verify a possible association between dizziness complaint and sleep quality in teachers.

Methods Cross-sectional study developed with 96 school teachers (mean age of $47.8 \pm 9.8$ years). To assess dizziness, an audiological assessment was performed, which was the same one used in routine audiological care (Miller protocol). The dizziness handicap inventory (DHI) was applied to those individuals who reported dizziness. To evaluated sleep quality, the Pittsburgh sleep quality index was used.

Results The prevalence of dizziness was $22.9 \%(n=22)$. Of these, $77.3 \%(n=17)$ were women, $63.6 \%(n=14)$ demonstrated poor sleep quality, and $54.5 \%(n=12)$ were young adults (27-48 years). In the comparison between the dizziness and the control groups, no statistically significant differences were found $(p>0.05)$. The analysis adjusted for the confounding variables showed a difference for men in the sleep efficiency variable $(p=0.043)$; young adults showed a statistically significant difference in the total score $(p=0.021)$ and total sleep time $(p=0.029)$. There was a moderate correlation between DHI and total time in bed $(p=0.036, r=0.497)$ and DHI and sleep efficiency $(p=0.014 ; r=-0.582)$.

Conclusion Dizziness influences the quality of sleep in teachers, especially that of the youngest and male patients. There was a moderate correlation between total time in bed, sleep efficiency, and $\mathrm{DHI}$, demonstrating that sleep quality should be considered an important factor in the assessment and rehabilitation process of dizziness.
\end{abstract}

\section{Introduction}

Although the physiological and psychological mechanisms involved in the development of sleep disorders remain received

August 2, 2019

accepted

March 10, 2020

published online

June 23, 2020
DOI https://doi.org/ 10.1055/s-0040-1710305. ISSN 1809-9777. similar throughout history, factors that potentiate these mechanisms are closely related to the sociocultural, technological and lifestyle trends that characterize an era. Growing evidence suggests that these advancements take their toll on (c) 2020. Fundação Otorrinolaringologia. All rights reserved.

This is an open access article published by Thieme under the terms of the Creative Commons Attribution-NonDerivative-NonCommercial-License, permitting copying and reproduction so long as the original work is given appropriate credit. Contents may not be used for commercial purposes, or adapted, remixed, transformed or built upon. (https://creativecommons.org/ licenses/by-nc-nd/4.0/)

Thieme Revinter Publicações Ltda., Rua do Matoso 170, Rio de Janeiro, RJ, CEP 20270-135, Brazil 
human functioning and health via their damaging effects on sleep quality, quantity, and timing. Additional behavioral lifestyle factors associated with poor sleep include weight gain, insufficient physical exercise, and consumption of substances such as caffeine, alcohol, and nicotine. Some of these factors have been implicated as self-help aids used to combat daytime sleepiness and impaired daytime functioning. ${ }^{1}$ Besides dealing with high workload and technological advancements, being a teacher is challenging with respect to the social context. There is increasing evidence that adverse social job characteristics challenge sleep quality. ${ }^{1,2}$

Dizziness is a common nonspecific sensation of disorientation or impairment in spatial perception and stability. ${ }^{3}$ The differential diagnosis of dizziness can be expansive but with a targeted history and physical examination, a correct diagnosis can often be established and appropriate treatment offered. The most common etiologies of dizziness include hypotension, Meniere disease, benign paroxysmal positional vertigo (BPPV), and other vertigos. Strokes and malignancies also can cause this symptom. ${ }^{4}$ However, poor habits such as lack of regular physical activity, low level of physical fitness, insufficient hours of sleep, and nutritional disorders are risk factors for several metabolic and circulatory changes that cause various symptoms, such as dizziness. ${ }^{5,6}$

It is known that the neurons that take part in the sleep stages are located in the pontine reticular formation and raphe nuclei, which are regions that also receive information for the otolithic organs. ${ }^{7,8}$ Dysfunctions in these organs could lead to interruptions in the sleep-wake cycle. ${ }^{8,9}$ Thus, it is possible that signals coming from the vestibular system are related with sleep regulation, as noted in actions such as walking, and riding a car as well as other movements that stimulate the vestibular system and help induce sleep. 8,10

The findings of another study strongly suggest that there are associations between sleep quality and some disease subtypes associated with dizziness. Therefore, it is important to consider sleep disturbance in patients with dizziness. ${ }^{6}$

A limited number of studies have examined sleep quality in patients with dizziness; among these, only a few studies have observed the association between sleep quality and dizziness in teachers. Thus, the present study had the objective of verifying a possible association between dizziness complaint and sleep quality in teachers.

\section{Methods}

This was a cross-sectional study, conducted in partnership with the (UEL-UNOPAR). It is part of a wider research named "PRÓ-MESTRE" "11. The project was approved by the human research ethics committee of the institution (protocol $n^{\circ}$ 742.355), and, prior to the beginning of the study, all patients were informed about the objectives and procedures to be performed and signed the informed consent term.

The inclusion criteria considered was to be a primary or secondary school teacher; being actively working at the time of the study; have more than 12 months of experience, and not having been removed from their duties for more than 30 days in the last 12 months. The exclusion criteria were individuals who presented physical and sensorial limitations that prevented the verification of dizziness and/or the inability to adopt the requested positions; those who had severely impaired hearing and/or visual acuity; patients who had ingested alcohol 24 hours before the evaluation; patients on anti-vertigo drugs, tranquilizers, or antidepressants; and patients who had undergone vestibular rehabilitation after medical discharge.

In order to carry out the audiological assessment research, the patients' clinical information was collected from routine care at the Speech-language-hearing Clinic, Audiology department, (Unopar), based on the Miller protocol for history, including questions about age, gender and tinnitus. ${ }^{12}$ Specific questions were used to investigate whether the sensation of dizziness was present or not, such as which ear was affected, if any; how often; when the symptom began; and what type of dizziness the participant has presented as chief complaint.

The Brazilian version of the dizziness handicap inventory $(\mathrm{DHI})^{13}$ was applied to those who reported dizziness. The $\mathrm{DHI}$ is a 25-item self-assessment scale designed to quantify the functional, emotional, and physical effects of dizziness and unsteadiness. $^{14}$

The assessment of sleep quality was obtained through interviews with the participants using the questionnaire. The instrument used was the Pittsburgh sleep quality index (PSQI). ${ }^{15}$ The instrument is composed of 19 issues in selfreporting. The questions are categorized into seven components, graded in scores from zero (no difficulty) to three (severe difficulty). The components of the PSQI are: C1subjective sleep quality, C2-sleep latency, C3-sleep duration, C4-habitual sleep efficiency, C5-sleep disturbances, C6-use of sleeping pills, and C7-daytime sleep dysfunction. The sum of the values assigned to the 7 components ranges from 0 to 21 in the total questionnaire score, indicating that the higher the number the worse the quality of sleep. A total score greater than five indicates that the individual is experiencing major dysfunctions in at least two components, or moderate dysfunction in at least three components. ${ }^{16} \mathrm{~A}$ total score $\leq 5$ was associated with good sleep quality and $>5$ associated with poor sleep quality. In addition to the categorical variables, the continuous variables reported in the questionnaire were also extracted: self-reported sleep latency (LAT), which would be the time that the person reports that it takes to fall asleep; total time in bed (TIB), which was the time the person stayed in bed; self-reported total sleep time (TST) was the time reported that the individual actually slept, and sleep efficiency (demonstrated in percentage) was calculated considering the ratio between (TST)/(TIB) X 100, with the due adjustments for TIB proposed by Buysse $2005 .{ }^{17}$ All variables were calculated according to the Buysse 2005 guidelines. ${ }^{17}$

\section{Statistical Analysis}

The Statistical Package for Social Sciences version 20.0 software (IMB Corp. Armonk, NY, USA) was used for statistical data analysis, with a $95 \%$ confidence interval $(95 \% \mathrm{CI})$ and a significance level of $5 \%(p<0.05)$ established for all tests used. The parametric distribution of the data was verified by 
the Shapiro Wilk test, as the assumption of normality was not assumed, and the Mann-Whitney test was used for continuous variables. The Spearman correlations test was performed to analyze the correlation between DHI and sleep quality parameters. The Chi-squared test was performed to analyze the association with categorical variables.

\section{Results}

We evaluated 96 teachers with mean age of $47.8 \pm 9.8$ years, $66.7 \%(n=64)$ of whom were females and $33.7 \%(n=32)$ of whom were male. Of these, $22.9 \%(n=22)$ self-reported dizziness; $77.3 \% \quad(n=17)$ were women; $31.8 \% \quad(n=7)$ reported tinnitus; 63.6\% $(n=14)$ were classified as "poor sleep quality" by the questionnaire; $54.5 \%(n=12)$ were young adults (age ranger $27-48$ years); and $72.7 \%(n=16)$ related to have slept 6 hours per night. The descriptive data about the sample are shown in -Table 1. (View - Table 1)

In the comparison between the dizziness and the control groups no statistically significant differences in the parameters evaluated for sleep quality were found $(p>0.05)$. These data are shown in - Table $\mathbf{2}$. Adjusted analyzes of the dizziness group exhibited a statistically significant difference for the total PSQI score $(p=0.001)$, thus demonstrating that participants with poor sleep quality were worse in the assessment.

Table 1 Descriptive data of the sample $(N=96)$

\begin{tabular}{|l|l|}
\hline General Characteristics & \\
\hline Gender & \\
\hline Female & $\mathrm{N}=64(66.7 \%)$ \\
\hline Male & $\mathrm{N}=32(33.3 \%)$ \\
\hline Age range (years) & \\
\hline $27-48$ years & $\mathrm{N}=52(54.2 \%)$ \\
\hline $49-65$ years & $\mathrm{N}=44(45.8 \%)$ \\
\hline Mean \pm standard deviation & $47.8 \pm 9.8$ \\
\hline Weekly workload & $32.5[40]^{\mathrm{a}}$ \\
\hline Time of service & $10[23]$ \\
\hline Groups & \\
\hline With dizziness & $\mathrm{N}=22(22.9 \%)$ \\
\hline Without dizziness & $\mathrm{N}=74(77.1 \%)$ \\
\hline PSQI parameters & \\
\hline Good sleep quality & $\mathrm{N}=44(45.8 \%)$ \\
\hline Poor sleep quality & $\mathrm{N}=52(54.2 \%)$ \\
\hline LAT (min) & $15[25]^{\mathrm{a}}$ \\
\hline TIB (min) & $390[90]^{\mathrm{a}}$ \\
\hline TST (min) & $360[97.5]^{\mathrm{a}}$ \\
\hline Sleep efficiency $\%)$ & $92.3[21.6]^{\mathrm{a}}$ \\
\hline Score total & $6[4]^{\mathrm{a}}$ \\
\hline
\end{tabular}

Abbreviations: LAT, sleep latency; TIB, total time in bed; PSQI, Pittsburgh sleep quality index; TST total sleep time.

a(median and interquartile range);
The analysis adjusted for the confounding variables showed a difference in the sleep efficiency and tinnitus categories $(p=0.030)$. Those who reported dizziness alone had lower sleep efficiency than those who reported dizziness and tinnitus. For men, there was a statistically significant difference in the sleep efficiency variable $(p=0.043)$, which indicated worse results. Young adults also showed a significant difference in the total score $(p=0.021)$ and TST $(p=0.029)$, which scored higher in the total score and reported less sleep time.

Moreover, there was a moderate correlation between DHI and TIB ( $p=0.036, r=0.497)$, which showed that as the DHI score increased, the TIB increased as well. Also, there was a moderate correlation between DHI and sleep efficiency $(p=0.014 ; \mathrm{r}=-0.582)$; in other words, as the DHI score increased, sleep efficiency decreased. These data are demonstrated in - Table 3. (View - Table 3).

\section{Discussion}

The objective of the present study was to verify a possible association between dizziness complaints and sleep quality in teachers. There were statistically significant differences in the male and young adult groups, and moderate correlation across DHI, TIB, and sleep efficiency, demonstrating that sleep quality was influenced by the presence of dizziness.

A study tested ${ }^{2}$ whether restraint sleep quality (defined as worse sleep quality before than during vacation) is related to time-related job stressors, job resources, and social job characteristics. Forty-eight elementary school teachers ( $42 \%$ of whom were women) participated both during the last week before and the first week after vacation. Before vacation, teachers were asked for the demographics and working conditions with reference to the last 30 days and sleep quality with reference to the last 7 days. After vacation, sleep quality during vacation was assessed and used as reference for working time sleep quality. The results showed that the mean levels of sleep quality increased during vacation. In teachers with restrained working time sleep quality (38\%), experiences of failure at work, social exclusion, and emotional dissonance were more frequent than in teachers with unrestrained working time sleep quality $(p<0.05)$. The groups did not differ in relation to time-related stressors, time control, and social support from supervisors. Emotion dissonance at work, social exclusion, and individual experience of failure seem to challenge sleep quality in teachers. ${ }^{2}$

Additional behavioral lifestyle factors associated with poor sleep include weight gain, insufficient physical exercise, and consumption of substances such as caffeine, alcohol, and nicotine. Some of these factors have been implicated as selfhelp aids used to combat daytime sleepiness and impaired daytime functioning. ${ }^{1}$

Although elderly people are more affected by sleep disorders, ${ }^{18,19}$ in this study, there was a statistically significant difference for young adults, which may be related to excessive use of computers and cell phones, excessive visual stimulation, and generally inadequate posture. This would 
Table 2 Comparative analyses of continuous and categorical variables between the subgroups with dizziness and without dizziness $(N=96)$

\begin{tabular}{|c|c|c|c|c|}
\hline Continuous variables & & $\begin{array}{l}\text { Dizziness } \\
(n=22)\end{array}$ & $\begin{array}{l}\text { No dizziness } \\
(n=74)\end{array}$ & $\begin{array}{l}P \text {-value } \\
\text { Mann-Whitney test }\end{array}$ \\
\hline Age (years) & & $48[11]^{\mathrm{a}}$ & 48 [15.5] & $p=0.853$ \\
\hline LAT (min) & & $10[17.5]$ & $15[25]$ & $p=0.459$ \\
\hline TIB (min) & & $405[120]$ & $390[90]$ & $p=0.781$ \\
\hline TST (min) & & $360[52.5]$ & $360[120]$ & $p=0.891$ \\
\hline Sleep efficiency (\%) & & $86.6[21.8]$ & $92.3[23.1]$ & $p=0.980$ \\
\hline Total score (PSQI) & & $6[5]$ & $6[4]$ & $p=0.937$ \\
\hline Categorical Variables & & $\mathrm{N}(\%)$ & $\mathrm{N}(\%)$ & $\begin{array}{l}\text { P } \\
\text { Chi-squared test }\end{array}$ \\
\hline \multirow[t]{2}{*}{ Gender } & Female & $17(77.3)$ & $47(63.5)$ & \multirow{2}{*}{$\begin{array}{l}p=0.345 \\
X^{2}=0.892\end{array}$} \\
\hline & Male & $5(22.7)$ & $27(36.5)$ & \\
\hline \multirow[t]{2}{*}{ Age range (years) } & $27-48$ & $12(54.5)$ & $40(54.1)$ & \multirow{2}{*}{$\begin{array}{l}p=1.000 \\
X^{2}=0.000\end{array}$} \\
\hline & $49-65$ & $10(45.5)$ & $34(45.9)$ & \\
\hline \multirow[t]{2}{*}{ Sleep quality (PSQI) } & Good sleep & $8(36.4)$ & $36(48.6)$ & \multirow{2}{*}{$\begin{array}{l}p=0.440 \\
X^{2}=0.595\end{array}$} \\
\hline & Poor sleep & $14(63.6)$ & $38(51.4)$ & \\
\hline \multirow[t]{2}{*}{ Tinnitus } & Yes & $7(31.8)$ & $11(14.9)$ & \multirow{2}{*}{$\begin{array}{l}p=0.116 \\
X^{2}=2.920\end{array}$} \\
\hline & No & $15(68.2)$ & $63(85.1)$ & \\
\hline \multirow[t]{2}{*}{ Hearing loss } & Yes & $3(13.6)$ & $12(16.2)$ & \multirow{2}{*}{$\begin{array}{l}p=1.000 \\
X^{2}=0.152\end{array}$} \\
\hline & No & $19(86.4)$ & $62(83.8)$ & \\
\hline \multirow[t]{2}{*}{ Diabetes } & Yes & $1(4.5)$ & $7(9.5)$ & \multirow{2}{*}{$\begin{array}{l}p=0.675 \\
X^{2}=0.685\end{array}$} \\
\hline & No & $22(95.5)$ & $67(90.5)$ & \\
\hline \multirow[t]{2}{*}{ Hypertension } & Yes & $4(18.2)$ & $17(22.9)$ & \multirow{2}{*}{$\begin{array}{l}p=0.773 \\
X^{2}=0.264\end{array}$} \\
\hline & No & $18(81.8)$ & $57(77.1)$ & \\
\hline \multirow[t]{2}{*}{ Aural fullness } & Yes & $4(18.2)$ & $14(18.9)$ & \multirow{2}{*}{$\begin{array}{l}p=1.000 \\
X^{2}=0.006\end{array}$} \\
\hline & No & $18(81.8)$ & $60(81.1)$ & \\
\hline
\end{tabular}

Abbreviations: LAT, sleep latency; TIB, total time in bed; TST, total sleep time; PSQI, Pittsburgh sleep quality index.

a (median and interquartile range);

Table 3 Spearman correlation between the dizziness handicap inventory and the Pittsburgh sleep quality index sleep parameters $(n=22)$

\begin{tabular}{|l|l|l|l|l|l|}
\hline & LAT & TIB & TST & EFIC & Total score PSQI \\
\hline & r; $P^{\mathbf{a}}$ & r; $P^{\mathbf{a}}$ & r; $P^{\mathbf{a}}$ & r; $P^{\mathbf{a}}$ & r; $P^{\mathbf{a}}$ \\
\hline DHI & $0.465 ; 0.094$ & $0.497 ; 0.036^{* *}$ & $-0.366 ; 0.199$ & $-0.582 ; 0.014^{* *}$ & $0.049 ; 0.868$ \\
\hline
\end{tabular}

Abbreviations: DHI, dizziness handicap inventory; EFIC, sleep efficiency; LAT, sleep latency; PSQI, Pittsburgh sleep quality index, total time in bed; TST, total sleep time.

${ }^{\mathrm{a}}(\mathrm{r}=$ spearman correlation value; $P=$ statistical difference.

${ }^{* *}$ (statistically significant difference).

justify dizziness/sleep disturbance symptoms in young adults. ${ }^{19}$ In the US, $96 \%$ of adults under the age of 30 reported using some form of technology. ${ }^{20}$ Studies have shown an association between the use of information technology and communication (computers, tablets, and cell phones) and poor sleep quality in young and middle-aged adults. ${ }^{21,22} \mathrm{~A}$ study evaluated 959 teachers, and it found that those who watched television $>120$ minutes/day had a higher likeli- hood of reporting poor sleep quality (PSQI $>5$ ) (odds ratio $=1.41 ; 95 \%$ confidence interval $=1.01 ; 1.98$ ) compared with those who watched television for up to 60 minutes/ day. ${ }^{23}$ In the case of teachers, they use technology for planning, carrying out their activities and professional training. Additionally, some of these teachers use technology in their moments of rest and leisure, so the younger age group may have been influenced by these factors. 
In this study, a significant difference was also found in relation to sleep efficiency in the group of male teachers. These data differ from another article that evaluated 252 patients with chronic dizziness and found statistically significant differences for female patients. ${ }^{24}$ The authors related that in patients with sleep disturbance, women had higher scores on the tests (DHI and PSQI) than men. However, this study was developed in patients with various types of dizziness and especially in the elderly (mean age $62.6 \pm 16.6$ years). In addition, the authors themselves recognize as a limitation the number of women included in comparison with the number of men, which may have caused imbalance in the relationship between genders. However, our data are in agreement with a report that investigated sleep problems among 1,245 public school teachers. Their results showed that male teachers working $>40$ hours per week were more likely to be young and less likely to have sleeping and leisure time, compared with those working $\leq 40$ hours per week. ${ }^{25}$ In our study, although there was no significant difference between the genders, the median weekly workload of men with dizziness was higher than that of women $(40 \mathrm{~h}$ and $25 \mathrm{~h}$, respectively), so the weekly workload of teachers with dizziness may impact the quality of the throughout life.

Another important finding of this study was the correlation between DHI and PSQI. Our study is according with a recent report that examined dizziness and sleep disturbance in 237 patients experiencing dizziness. There was association between PSQI and DHI for all subtypes of dizziness evaluated $(p<0.001)$. The authors strongly suggest that there are associations between sleep quality and some disease subtypes associated with dizziness. ${ }^{6}$ This demonstrates how the complaint of dizziness alone, as reported in our study, can already influence the quality of sleep. Another paper already mentioned above ${ }^{24}$ also found interaction between total DHI and its subscales and PSQI. Their results demonstrated that the presence of sleep disturbance was related to increased DHI total, DHI-E, and DHI-F scores.

Thus, it can be observed that dizziness acts as a factor of impact on sleep quality. It can also be an additional factor among the various symptoms derived from the attributions related to the activity of teaching.

Some limitations of this study should be considered: Emotional factors were not evaluated; however, none of the evaluated teachers were separated from their functions for more than 30 days in the 12 months prior to the evaluations for psychiatric reasons. In addition, few studies that relate the variables dizziness and sleep quality in teachers were found. This may have made it difficult to compare the findings.

\section{Conclusion}

The complaint of dizziness influences the quality of sleep in teachers and mainly young and male subjects were affected. There was a moderate correlation between TIB, sleep efficiency, and DHI, which demonstrated that sleep quality should be considered as an important factor in the assessment and rehabilitation process of dizziness. Further studies are needed to confirm these findings.
Conflicts of Interest

The authors have no conflicts of interest to declare.

Funding Information

Fundação Nacional de Desenvolvimento do Ensino Superior Particular (FUNADESP).

\section{References}

1 Shochat T. Impact of lifestyle and technology developments on sleep. Nat Sci Sleep 2012;4:19-31

2 Kottwitz MU, Gerhardt C, Pereira D, Iseli L, Elfering A. Teacher's sleep quality: linked to social job characteristics? Ind Health 2018;56(01):53-61

3 Neuhauser HK, Radtke A, von Brevern M, Lezius F, Feldmann M, Lempert T. Burden of dizziness and vertigo in the community. Arch Intern Med 2008;168(19):2118-2124

4 McKinley JE, Perkins A. Neurologic Conditions: Dizziness and Vertigo. FP Essent 2019;477:29-39

5 Schultz AR, Neves-Souza RD, Costa VdeS, Meneses-Barriviera CL, Franco PP, Marchiori LL. Is There a Possible Association between Dietary Habits and Benign Paroxysmal Positional Vertigo in the Elderly? The Importance of Diet and Counseling. Int Arch Otorhinolaryngol 2015;19(04):293-297

6 Kim SK, Kim JH, Jeon SS, Hong SM. Relationship between sleep quality and dizziness. PLoS One 2018;13(03):e0192705

7 Hobson JA. The cellular basis of sleep cycle control. In: Weitzman ED, ed. Advances in sleep research, vol 1. New York: Spectrum; 1974:217-249

8 Andrade MC Junior, Stefanini R, Gazzola JM, Haddad FL, Ganan,a FF. Individuals with peripheral vestibulopathyand poor quality of sleep are at a higher risk for falls. Rev Bras Otorrinolaringol (Engl Ed) 2019. Doi: 10.1016/j.bjorl.2019.10.013

9 Bolton PS, Goto T, Schor RH, Wilson VJ, Yamagata Y, Yates BJ. Response of pontomedullary reticulospinal neurons to vestibular stimuli in vertical planes. Role in vertical vestibulospinal reflexes of the decerebrate cat. J Neurophysiol 1992;67(03): 639-647

10 Yates BJ. Autonomic reaction to vestibular damage. Otolaryngol Head Neck Surg 1998;119(01):106-112

11 Birolim MM, Mesas AE, González AD, Santos HG, Haddad MCFL, Andrade SM. Trabalho de alta exigência entre professores: associações com fatores ocupacionais conforme o apoio social. Ciênc. saúde coletiva 2019;24(04):1255-1264

12 Miller MH. A integração dos achados audiológicos. In: Katz J, ed. Tratado de audiologia clínica, 3 ed. São Paulo: Manole; 1999: 268-270

13 Castro ASO, Gazzola JM, Natour J, Ganança FF. Versão brasileira do Dizziness Handicap Inventory. Pro Fono Atual. Cient. 2007;19 (01):97-104

14 Jacobson GP, Newman CW, Hunter L, Balzer GK. Balance function test correlates of the Dizziness Handicap Inventory. J Am Acad Audiol 1991;2(04):253-260

15 Buysse DJ, Reynolds CF III, Monk TH, Berman SR, Kupfer DJ. The Pittsburgh Sleep Quality Index: a new instrument for psychiatric practice and research. Psychiatry Res 1989;28(02):193-213

16 Araujo PAB, Sties SW, Wittkopf PG, et al. Índice da qualidade do sono de Pittsburgh para uso na reabilitação cardiopulmonar e metabólica. Rev Bras Med Esporte 2015;21(06):472-475

17 Buysse DJ. Pittsburgh Sleep Quality Index. Form administration instructions, references and scoring [Internet]. 2005. Available at: https://www.sleep.pitt.edu/instruments/

18 Menon-Miyake MA, Santana GG, Menon-Miyake M, MenonMiyake M. Sleeping disorders and vestibular symptoms. Rev Equilíbrio Corporal Saúde. 2015;6(02):60-66

19 Oliveira BHD, Yassuda MS, Cupertino APFB, Neri AL. [Relations between sleep patterns, perceived health and socioeconomic 
variables in a sample of community resident elders: PENSA Study]. Cien Saude Colet 2010;15(03):851-860

20 Gradisar M, Wolfson AR, Harvey AG, Hale L, Rosenberg R, Czeisler CA. The sleep and technology use of Americans: findings from the National Sleep Foundation's 2011 Sleep in America poll. J Clin Sleep Med 2013;9(12):1291-1299

21 Brunborg GS, Mentzoni RA, Molde $\mathrm{H}$, et al. The relationship between media use in the bedroom, sleep habits and symptoms of insomnia. J Sleep Res 2011;20(04):569-575

22 Thomée S, Eklöf M, Gustafsson E, Nilsson R, Hagberg M. Prevalence of perceived stress, symptoms of depression and sleep disturbances in relation to information and communication tech- nology (ICT) use among young adults - an explorative prospective study. Comput Human Behav 2007;23:1300-1321

23 de Souza SCS, Campanini MZ, de Andrade SM, González AD, de Melo JM, Mesas AE. Watching television for more than two hours increases the likelihood of reporting poor sleep quality among Brazilian schoolteachers. Physiol Behav 2017;179:105-109

24 Sugaya N, Arai M, Goto F. The effect of sleep disturbance in patients with chronic dizziness. Acta Otolaryngol 2017;137(01):47-52

25 Bannai A, Ukawa S, Tamakoshi A. Long working hours and sleep problems among public junior high school teachers in Japan. J Occup Health 2015;57(05):457-464 